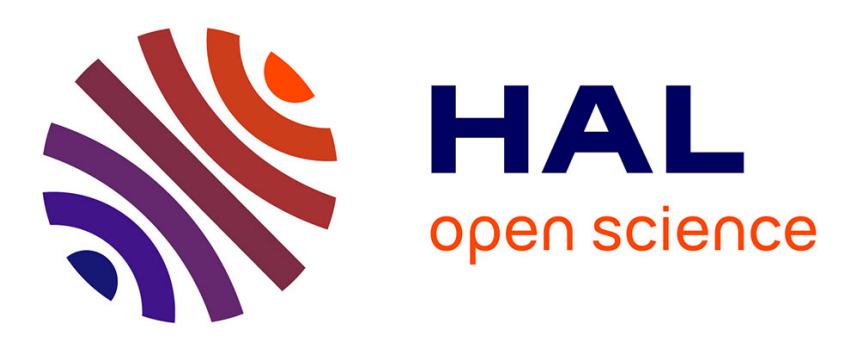

\title{
X-ray phase contrast microtomography for the analysis of the fibrous microstructure of SMC composites
}

\author{
Thaihung Le, Pierre J.J. Dumont, L. Orgéas, D. Favier, Luc Salvo, Elodie
} Boller

\section{- To cite this version:}

Thaihung Le, Pierre J.J. Dumont, L. Orgéas, D. Favier, Luc Salvo, et al.. X-ray phase contrast microtomography for the analysis of the fibrous microstructure of SMC composites. Composites Part A: Applied Science and Manufacturing, 2008, 39, pp.91-103. 10.1016/j.compositesa.2007.08.027 . hal-00374957

\section{HAL Id: hal-00374957 \\ https://hal.science/hal-00374957}

Submitted on 28 Feb 2019

HAL is a multi-disciplinary open access archive for the deposit and dissemination of scientific research documents, whether they are published or not. The documents may come from teaching and research institutions in France or abroad, or from public or private research centers.
L'archive ouverte pluridisciplinaire HAL, est destinée au dépôt et à la diffusion de documents scientifiques de niveau recherche, publiés ou non, émanant des établissements d'enseignement et de recherche français ou étrangers, des laboratoires publics ou privés. 


\title{
X-ray phase contrast microtomography for the analysis of the fibrous microstructure of SMC composites
}

\author{
T.-H. Le ${ }^{\text {a }}$, P.J.J. Dumont ${ }^{\text {b }}$, L. Orgéas ${ }^{\text {a,* }}$, D. Favier ${ }^{\text {a }}$, L. Salvo ${ }^{\text {c }}$, E. Boller ${ }^{\text {d }}$ \\ ${ }^{a}$ Laboratoire Sols-Solides-Structures (3S), CNRS, Universités de Grenoble (INPG-UJF), BP 53, 38041 Grenoble Cedex 9, France \\ ${ }^{\mathrm{b}}$ Laboratoire de Génie des Procédés Papetiers (LGP2), CNRS-INPG-EFPG, BP 65, 461 rue de la Papeterie, 38402 Saint-Martin-d'Hères Cedex 9, France \\ ${ }^{\mathrm{c}}$ Laboratoire de Génie Physique et Mécanique des Matériaux (GPM2), CNRS-INPG, 101, rue de la Physique, 38402 Saint-Martin-d'Hères Cedex, France \\ ${ }^{\mathrm{d}}$ European Synchrotron Radiation Facility (ESRF), ID 19 Topography \& Microtomography Group, 38043 Grenoble Cedex, France
}

\begin{abstract}
X-ray microtomographs of samples cut from non-deformed and compression moulded Sheet Moulding Compounds (SMC) plates have been analysed using the phase contrast mode. Results emphasise a significant decrease of the porosity after moulding, this phenomenon being enhanced with increasing the initial SMC temperature. They also show that pronounced migration of the polymer-matrix occurs through the thickness of the plates during compression moulding. The substructures of compression moulded plates through their thickness exhibit a core zone sandwiched between upper and lower skins. Inside the skins, the fibre content and the porosity are weaker than in core zones, and fibre-bundles are highly broken up. On the contrary, fibre-bundles remain preserved in core zones. Therein, the significant flattening and widening of bundles, their weak bending as well as their orientation have been quantified.
\end{abstract}

Keywords: A. Polymer-matrix composites (PMCs); B. Fibrous microstructure; B. Porosity; D. X-ray microtomography; E. Compression moulding

\section{Introduction}

Sheet Moulding Compounds (SMC) are widely used by the car industry to produce cost-efficient lightweight and large body panels. SMC form continuous sheets (thickness $\approx 2-3 \mathrm{~mm}$ ) containing approximately $25 \mathrm{wt} \%$ chopped fibre-bundle mats embedded in a thick thermoset matrix essentially made of mineral fillers (e.g. $\approx 45 \mathrm{wt} \%$ of $\left.\mathrm{CaCO}_{3}\right)$, polyester resin $(\approx 25 \mathrm{wt} \%)$ and other additives $(\approx 5 \mathrm{wt} \%)$. Usually, fibre-bundles are composed of approximately 200 glass fibres, which length and diameter equal $10-50 \mathrm{~mm}$ and $15 \mu \mathrm{m}$, respectively. In order to produce parts, SMC sheets are first cut, stacked and placed in a hot mould $\left(\approx 150{ }^{\circ} \mathrm{C}\right)$. Then, they are squeezed at a closure velocity varying between 0.1 and $10 \mathrm{~mm} \mathrm{~s}^{-1}$. Once the mould is filled, it is maintained closed during the curing

\footnotetext{
* Corresponding author. Tel.: +334768270 73; fax: +33476827043. E-mail address: Laurent.Orgeas@hmg.inpg.fr (L. Orgéas).
}

stage (from 60 to $120 \mathrm{~s}$ ). Finally the moulded part is ejected. Major microstructural changes can occur during this compression moulding stage, such as evolution of spatial and orientation distributions of fibre-bundles, formation and evolution of voids... These changes have significant impacts on final physical and mechanical properties of moulded parts $[34,40]$ as well as on their surface aspects (pinholes, craters, surface waviness...) [22]. In order to characterise them, many techniques have been investigated. For instance the charring and weighting technique $[11,17]$ permits to determine the average mass fraction of fibres within samples cut from SMC parts. If this type of analysis is useful to study the phenomenon of matrix migration charring samples entirely destroys fibre-bundle networks as well as the geometry of deformed bundles. Optical or scanning electron microscopy can also be used to bring precious information on the impregnation of bundles by the matrix [15]. Measuring the orientation of bundles by analysing the shapes of bundles' cross-sections 
on the obtained micrographs, as it has been developed for composites reinforced with monofilament short fibres $[7,21]$, is however very difficult due to the complexity of the geometry of bundles. Absorption X-ray radiography can also be used to characterise the orientation of fibres [39]. If it is a non-destructive method, information that can be gained (preferred directions of microstructures within the composites) is averaged through the thickness of parts. Likewise, there is a small mismatch between the absorption properties of the polymer-matrix (which contains a large amount of $\mathrm{CaCO}_{3}$ fillers) and the glass fibres so that it is impossible to distinguish between these two phases. More recently, Comte et al. [15] analysed a nondeformed and non-cured SMC sample using the X-ray absorption microtomography. With this technique, it was possible to measure the pore content inside the sample. Nonetheless, as in the case of X-ray radiography, the absorption mode did not give satisfactory results to observe bundles inside the tested SMC sample. Consequently, it seems very difficult to learn easily, with a single observation technique, a lot on the microstructure of a given deformed SMC sample.
In the present study, we have tried to overcome the above difficulties. For that purpose, small cylindrical samples were cut from SMC plates (Section 2) that had been compression moulded in an earlier work [17]. They have been scanned using a X-ray microtomograph and the phase contrast imaging mode. This observation mode allows a better distinction of the filled polymer-matrix and the glass fibre-bundles (Section 3). Experimental observations are presented in Section 4. Trends, which can be deduced from them, are discussed in the last section.

\section{Materials and compression moulding experiments}

The SMC plates that were compression moulded in [17] were made of standard low profile SMC, which rheology was studied in $[16,28]$. Briefly, the initial sheets had an average thickness of approximately $2.5-3 \mathrm{~mm}$ and were composed of a polyester resin that was mainly filled with $\mathrm{CaCO}_{3}$ mineral fillers of typical diameter $2 \mu \mathrm{m}$ and glass fibre-bundles $(\approx 25 \mathrm{wt} \%)$, with approximately elliptical cross-section (major axis $a_{00} \approx 0.66 \mathrm{~mm}$ and minor axis
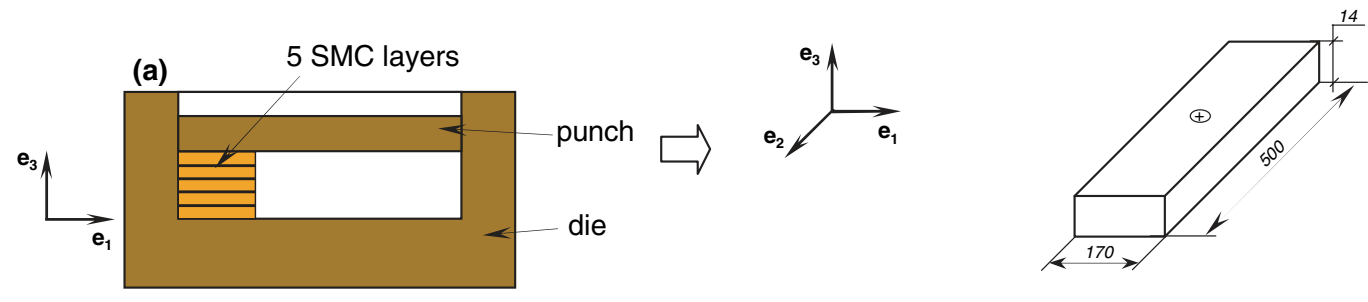

Plate $\mathrm{A}\left(30^{\circ} \mathrm{C}\right)$
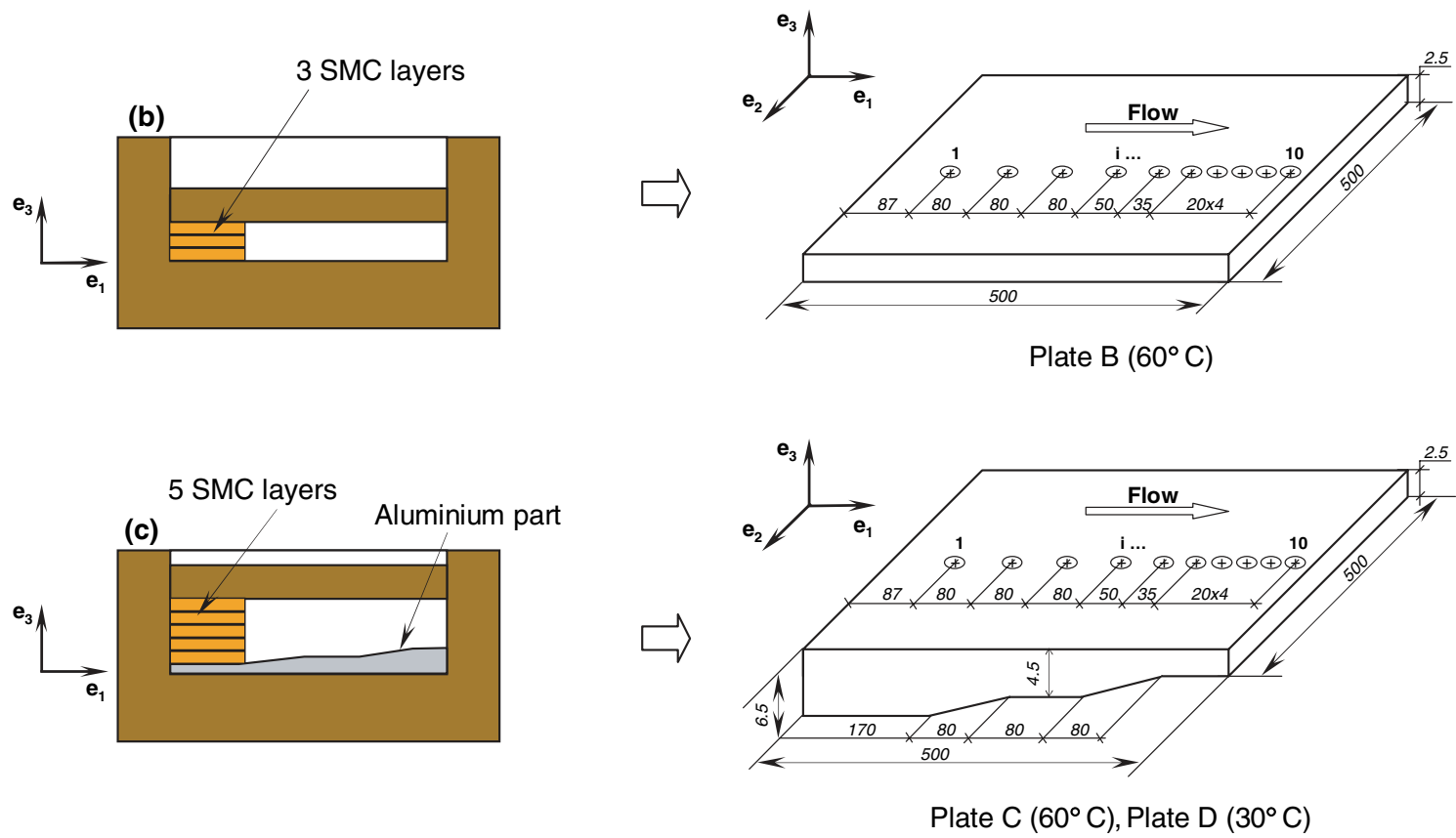

Fig. 1. Schematic representations of the side views of the standard and modified moulds with the initial charges of SMC (left) used to produce plates A (a), $\mathrm{B}$ (b) and C and D (c) (right). Circles drawn on the surfaces of the compression moulded plates indicate the location of cylindrical samples that were cut and used for X-ray microtomography. All dimension units are in $\mathrm{mm}$. 
$b_{00} \approx 0.06 \mathrm{~mm}$ ), each of them containing 200 fibres of diameter $d \approx 15 \mu \mathrm{m}$ and length $l=25 \mathrm{~mm}$.

The microstructures of four plates of the previous study have been characterised here, all the considered plates being compressed with an axial punch velocity of $1 \mathrm{~mm}$ $\mathrm{s}^{-1}$ and with an initial charge put in the left part of the mould, see Fig. 1. Moreover, the maximum average mould closing pressure $p$ was fixed to $10 \mathrm{MPa}$. The first plate, i.e. plate A (cf. Fig. 1a), was obtained without material flow, i.e. just by curing by simple contact with the upper and lower parts of the mould a SMC charge made of five SMC stacked layers (initially at room temperature, i.e. $30^{\circ} \mathrm{C}$ ). The second plate, i.e. plate B (Fig. 1b), was moulded in the standard mould from an initial SMC charge made of three stacked layers preheated at $60^{\circ} \mathrm{C}$ for 10 min. Two last plates, i.e. plates C and D (Fig. 1c), were moulded in the modified mould from an initial stack of five SMC layers. Among these two plates, plate $\mathrm{C}$ was initially preheated at $60^{\circ} \mathrm{C}$ for $10 \mathrm{~min}$ and plate $\mathrm{D}$ was obtained from a SMC charge initially at room temperature.

\section{X-ray microtomography}

Cylindrical samples (height $2 \mathrm{~mm}<h<14 \mathrm{~mm}$ and diameter $d=10 \mathrm{~mm}$ ) were first cut using a water-jet cutting machine in different locations of the produced plates A, B, $\mathrm{C}$ and D. Circles drawn on the surface of the plates of the right-hand side of Fig. 1 indicate the locations of these samples. For the non-deformed plate A, only one sample was cut in the middle of the plate. For the other plates, 10 cylindrical samples were cut along a line parallel to the flow direction. Samples were then scanned using the X-ray source provided at the European Synchrotron Radiation Facility (Grenoble, France). They were exposed to an electron beam energy of $35 \mathrm{keV}$ as a $2048 \times 2048 \mathrm{CCD}$ camera took pictures of 1500 projections over $180^{\circ}$ of the cylindrical samples (scanning time $\approx 6 \mathrm{~min}$ ). A specially designed software was used to reconstruct 3D grey scale images (256 grey levels) of the scanned samples with a voxel size of $7.5 \mu \mathrm{m}$. Notice that for technical reasons, it has not been possible to scan samples $\mathrm{C}_{1}$ and $\mathrm{C}_{9}$, and to
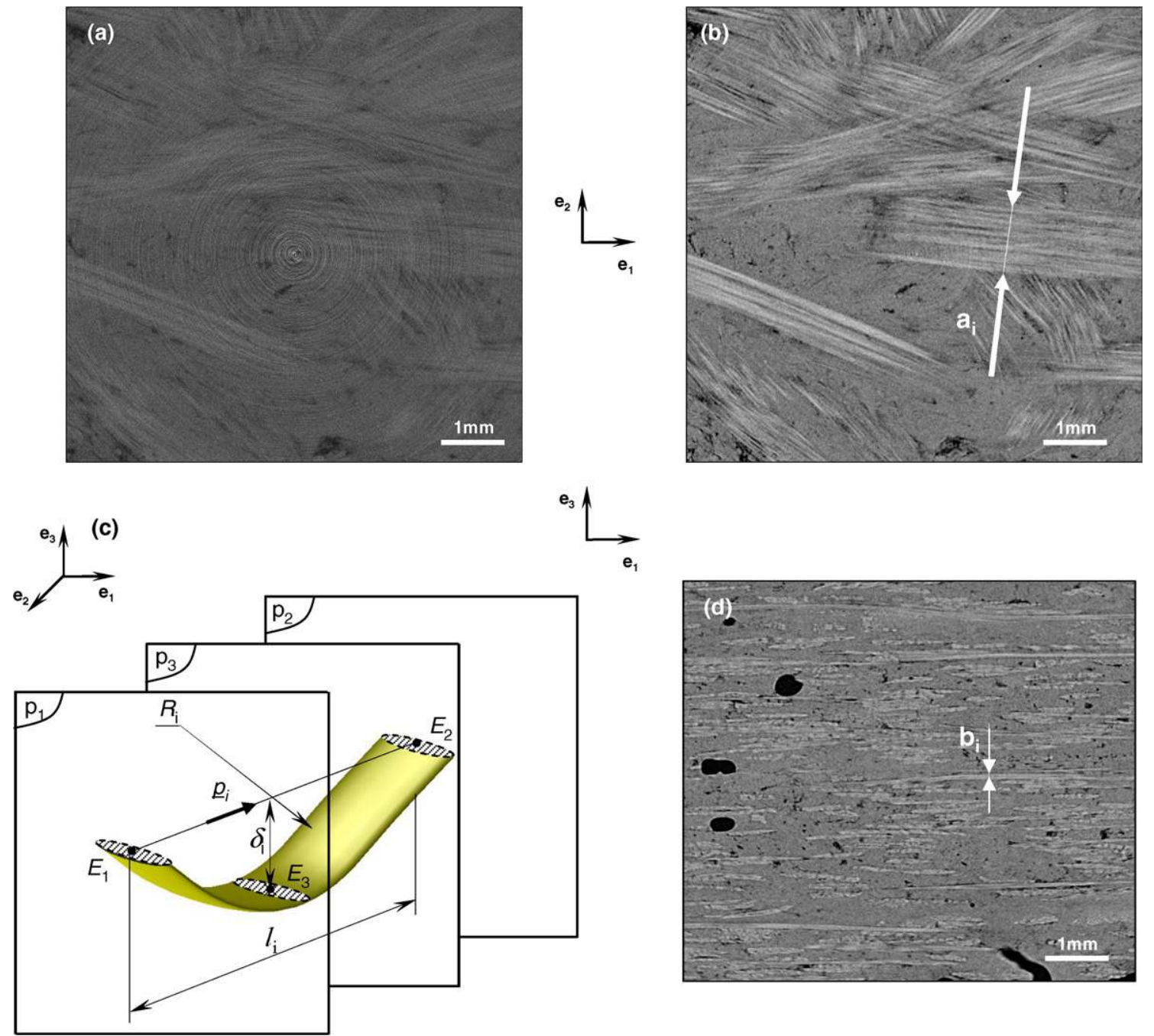

Fig. 2. (a-b) 2D micrographs showing the same cross-section, i.e. at $x_{3}=h / 2$, taken from sample $\mathrm{B}_{5}$. They have been obtained by X-ray microtomography using the absorption mode (a) or the phase contrast mode (b). Polymer-matrix is in dark grey, fibres are in light grey and pores are in black. Methods used to characterise the width $a_{i}$ of a given bundle (b), its orientation vector $\underline{\boldsymbol{p}}_{i}$, curvature radius $R_{i}$ and deflection $\delta_{i}$ (c), and its thickness $b_{i}$ along $\underline{\boldsymbol{e}}_{3}$ (d). 
get a full scan of sample A, which first SMC layer has been truncated.

\subsection{Absorption vs. phase contrast imaging modes}

The X-ray microtomograph given in Fig. 2a has been obtained with the common absorption imaging mode with a small focal distance of $30 \mathrm{~mm}$. It represents an in-plane cross-section taken in the middle of sample $\mathrm{B}_{5}$. From such a microtomograph, it is extremely difficult to distinguish the fibre-bundles from the filled polymer-matrix, as already mentioned by [15]. This is mainly ascribed to the weak difference between the absorption properties of the glass fibre-bundles and the $\mathrm{CaCO}_{3}$ mineral fillers contained in the polyester matrix. The micrograph shown in Fig. $2 b$ represents the same cross-section than the one of Fig. 2a, but obtained by using the phase contrast mode with a lar- ger focal distance of $310 \mathrm{~mm}[6,12,14]$. As evident from these two microtomographs, the observation of bundles and pores inside the filled polymer-matrix is much easier using the phase contrast mode than the absorption mode, even if the contrast between the fibres and the matrix is still not excellent. Consequently, for all subsequent analyses, samples were scanned using the phase contrast mode.

\subsection{Determination of the volume fractions of pores and fibres}

By using the free software ImageJ, the $3 \mathrm{D}$ grey scale images were first "cleaned" with a standard 3D median filter in order to reduce the random noise. In order to obtain $3 \mathrm{D}$ binary renderings of the porosity as well as the bundle networks, scanned volumes were subjected to a grey scale thresholding followed by a binarisation. This also permits to get an estimation of the porosity (and the volume frac-
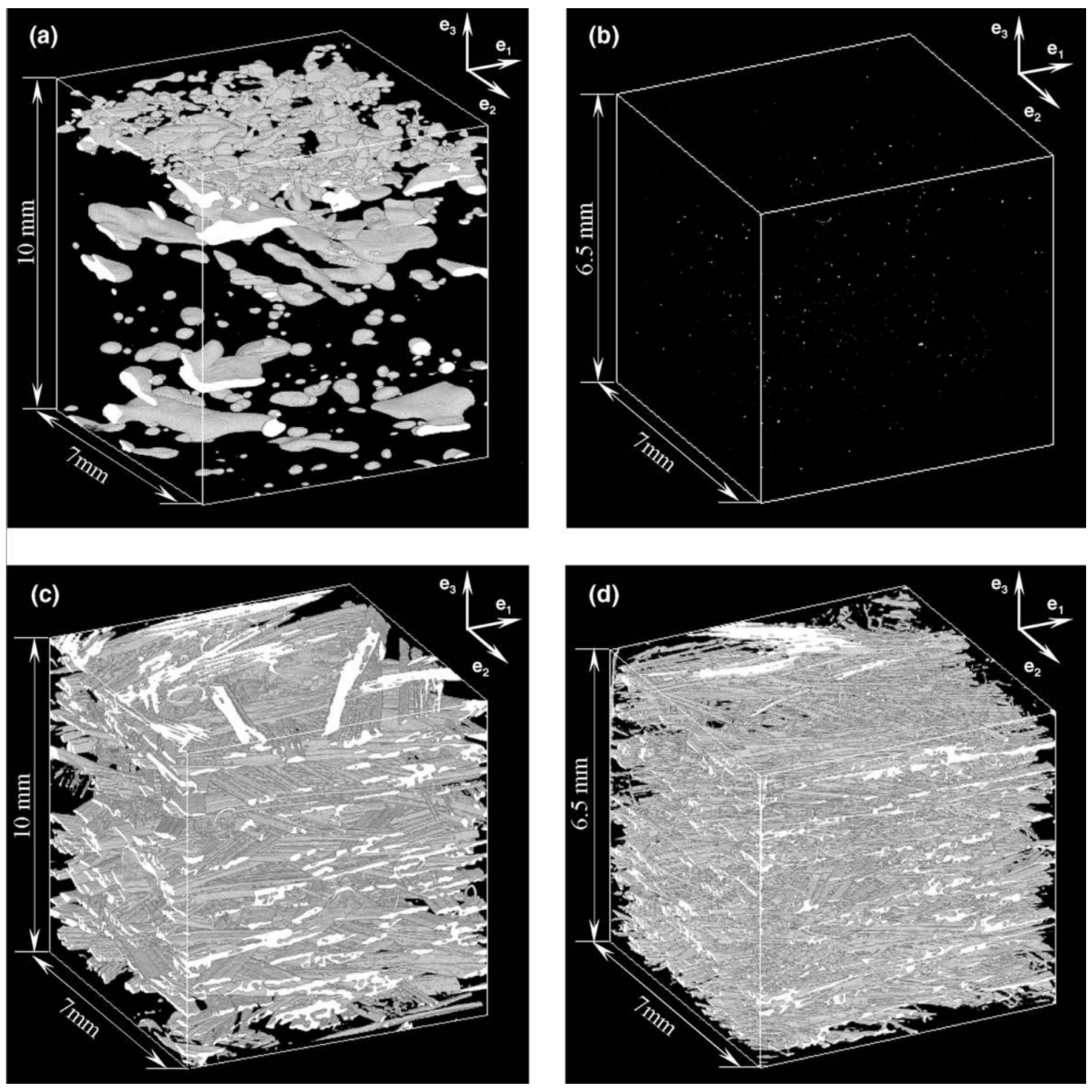

Fig. 3. 3D micrographs taken from samples $A$ (a and c, non-deformed sample, $0 \mathrm{~mm}<x_{3}<10 \mathrm{~mm}$ ) and $\mathrm{C}_{2}$ (b and d, after compression moulding, $0 \mathrm{~mm}<x_{3}<6.5 \mathrm{~mm}$ ), showing the pores ( $\mathrm{a}$ and $\mathrm{b}$ ) and the bundles ( $\mathrm{c}$ and $\mathrm{d}$ ). They have been obtained by X-ray microtomography with the phase contrast mode, followed by a filtering, a thresholding and a binarisation. 
tion of fibres), defined as the ratio (number of white voxels)/(total number of voxels) within a given volume. Two measurements of volume fractions will be used in the following: (i) $\phi$ and $f$, respectively defined as the volume fractions of pores and fibres in a given stack of horizontal voxels, i.e. voxels lying in a given plane parallel to $\left(\underline{e}_{1}\right.$, $\underline{\boldsymbol{e}}_{2}$ ), and (ii) $\langle\phi\rangle$ and $\langle f\rangle$, respectively defined as the average volume fractions of pores and fibres in a whole analysed sample. Note that a good accuracy of $\pm 0.1 \%$ is obtained for the porosity $\phi$. Conversely, due to the rather pore contrast between the fibre and the matrix, a rather large scattering of $\pm 1.5 \%$ is recorded for the evolution of the volume fraction of fibres $f$.

\subsection{Characterisation of fibre-bundle microstructures}

As shown from the 3D views of Fig. 3c and d, fibre-bundle networks look like complex and strongly entangled microstructures from which it has not been possible to extract easily and automatically (from an image processing routine) each bundle in order to analyse its geometrical properties [36]. Instead, this was done "manually" and directly from the 3D grey scale images, using the softwares ImageJ and Matlab [19]. Five bundle descriptors were defined and measured in order to characterise the bundles' geometry: orientation, bending, thickness, width and crosssection area. Notice that these descriptors are meaningful only in zones where bundles have kept their integrity (see Section 4.2). The following points briefly describe the methods used to measure them.

- The scheme sketched in Fig. 2c illustrates the method used to obtain a measurement of the orientation of bundles. It first consists in picking (with an error of $\approx \pm 0.02 \mu \mathrm{m}$ ) the centres $E_{1}$ and $E_{2}$ of two cross-sections $S_{1}$ and $S_{2}$ located at the extremities (i.e. in-plane $P_{1}$ and $P_{2}$ ) of the visible parts of $N$ bundles contained in a scanned volume. It is then possible to define unit orientation vectors $\boldsymbol{p}_{i}=\boldsymbol{E}_{\mathbf{1}} \boldsymbol{E}_{\mathbf{2}} /\left\|\boldsymbol{E}_{\mathbf{1}} \boldsymbol{E}_{\mathbf{2}}\right\|$ for each bundle $i$. It is also possible to describe the global orientation of the considered bundle network with the second order orientation tensor $\boldsymbol{A}$ [2]. As already pointed out previously [19], such a measurement of the bundle orientation is meaningful only if the bending of bundles is weak (see Section 4.2), but also if the number $N$ of selected bundles is sufficiently high. Typically, in each analysed 3D images, it was possible to measure the orientation of $N=75$ bundles by scanning the volumes along the three directions $\underline{\boldsymbol{e}}_{1}, \underline{\boldsymbol{e}}_{2}$ and $\underline{\boldsymbol{e}}_{3}$.

- Fig. 2c also illustrates the method used to estimate the bending of bundles. For that purpose, it was arbitrarily assumed that the bending of a bundle $i$ could be approximated by a pure bending with a constant curvature radius $R_{i}$. This hypothesis may be valid if the bending of bundles is weak and not too complex [19]. Hence, the method consists in picking three points per bundle: the two end points $E_{1}$ and $E_{2}$ defined previously and the centre $E_{3}$ of the cross-section $S_{3}$ belonging to $P_{3}$. This allows to calculate the bending radius $R_{i}$ but also the deflection $\delta_{i}$ of bundles, from the knowledge of $R_{i}$ and the length $l_{i}=\left\|\boldsymbol{E}_{\mathbf{1}} \boldsymbol{E}_{\mathbf{2}}\right\|$. It is then possible to define the average dimensionless deflection $\left\langle\delta^{*}\right\rangle$ in the considered volume:

$$
\left\langle\delta^{*}\right\rangle=\frac{1}{N} \sum_{i=1}^{N} \frac{\delta_{i}}{l_{i}}=\frac{1}{N} \sum_{i=1}^{N} \frac{R_{i}}{l_{i}}\left(1-\sqrt{1-\left(l_{i} / 2 R_{i}\right)^{2}}\right) .
$$

- Fig. $2 \mathrm{~b}$ and $\mathrm{d}$ shows how the width $a_{i}$ in $\left(\underline{\boldsymbol{e}}_{1}, \underline{\boldsymbol{e}}_{2}\right)$ as well as the thickness $b_{i}$ along $\underline{e}_{3}$ of a bundle $i$ have been measured (with an accuracy of $\approx \pm 0.02 \mathrm{~mm}$ ). From these measurements, the average dimensionless width $\left\langle a^{*}\right\rangle$ and thickness $\left\langle b^{*}\right\rangle$ are introduced:

$$
\left\langle a^{*}\right\rangle=\frac{\langle a\rangle}{\left\langle a_{0}\right\rangle}=\sum_{i=1}^{N} a_{i} / \sum_{i=1}^{N} a_{0 i},\left\langle b^{*}\right\rangle=\frac{\langle b\rangle}{\left\langle b_{0}\right\rangle}=\sum_{i=1}^{N} b_{i} / \sum_{i=1}^{N} b_{0 i},
$$

where $a_{0 i}$ and $b_{0 i}$ are estimated from the non-deformed sample A.

\section{Results}

\subsection{Volume fraction of fibres and porosity}

Fig. $4 \mathrm{a}$ and $\mathrm{b}$ show the evolutions of the volume fraction of fibres $f$ and the porosity $\phi$ through the thickness of the non-deformed sample A. Fig. 4c, d, and e give the variation of the fibre volume fraction $f$ through the thicknesses of all scanned deformed samples $\mathrm{B}_{i}, \mathrm{C}_{i}$ and $\mathrm{D}_{i}$. The evolution of the average volume fraction of fibres $\langle f\rangle$ along the length $x_{1}$ of moulded plates $\mathrm{B}, \mathrm{C}$ and $\mathrm{D}$ is given in Fig. 5. Lastly, a typical evolution of the porosity through the thickness of the deformed samples is illustrated in Fig. 6a in case of sample $C_{2}$, whereas Fig. $6 b$ shows the profile of the average porosity $\langle\phi\rangle$ along the length $x_{1}$ of plates B, C and D. These four figures bring up the following remarks.

- As seen from Fig. 4a, a "crenellated" profile of the fibre content $f$ is observed in the non-deformed sample A. Zones where $f$ attains its minimum values correspond to the interfaces between the five SMC layers of the initial stack used for this moulding, see Fig. 1a. These interfaces are indicated by dashed-dotted lines in Fig. 4a. Inside each layer, there is a systematic microstructure made of upper and lower skins, in which $f$ is much lower than in a core zone, where $f$ is roughly constant. Such a fibre content profile is induced during processing of SMC layers, i.e. during impregnation of fibre-bundle mats by the polymer-matrix. The thicknesses $\mathrm{e}^{+}, \mathrm{e}^{-}$and $\mathrm{e}_{c}$ of the upper "+" and lower " skins "s" as well as the core "c" zone have been estimated in the five layers, (Fig. 4a). In average, $\mathrm{e}^{+} \approx 0.27 \mathrm{~mm}$ is very close to $\mathrm{e}^{-} \approx 0.28 \mathrm{~mm}$. The 

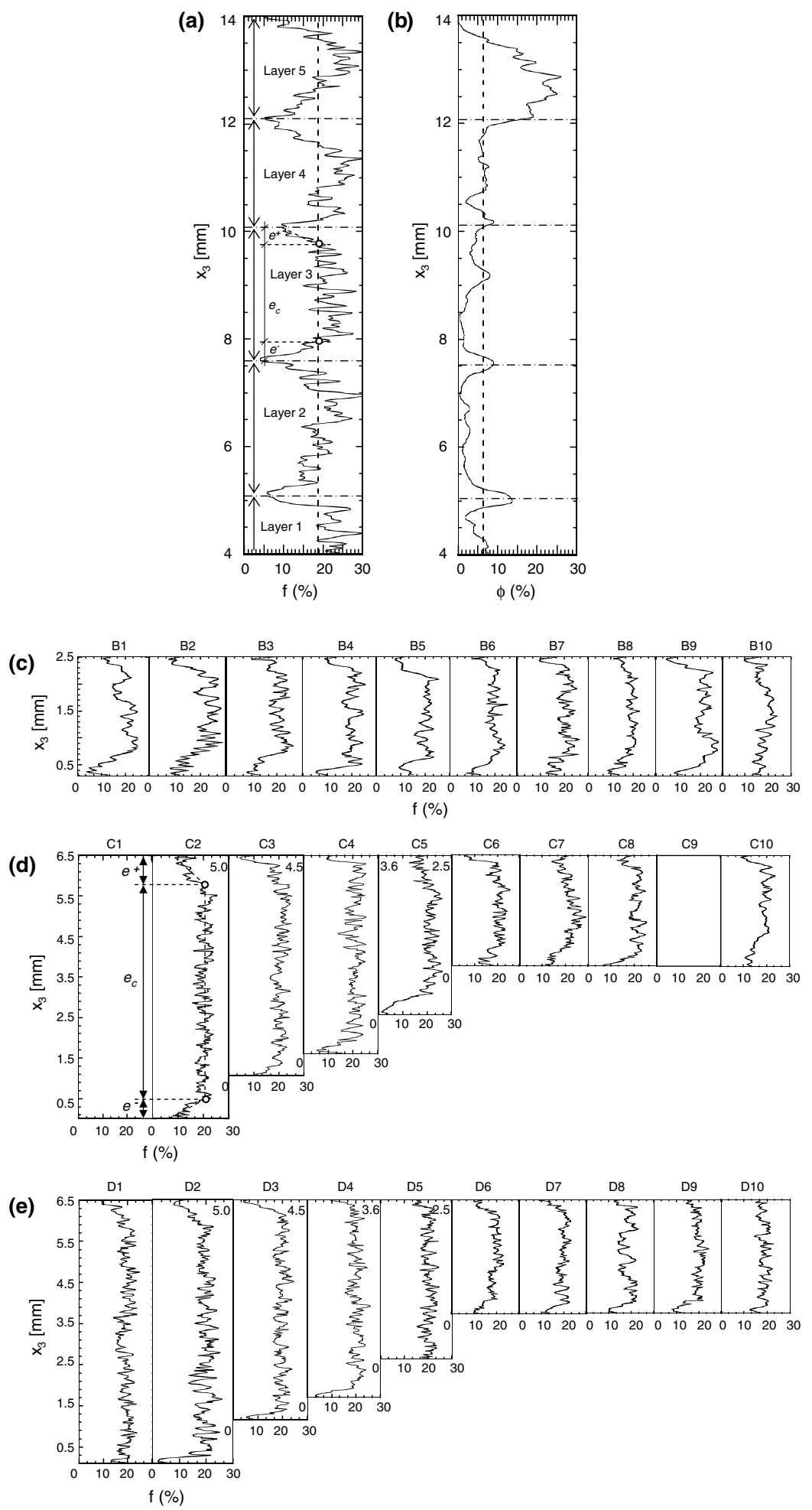

Fig. 4. Evolution (a) of the fibre volume fraction $f$ and (b) of the porosity $\phi$ through the thickness $x_{3}$ of the non-deformed sample A. Evolution of the fibre volume fraction $f$ through the thickness $x_{3}$ of the samples cut from plates $\mathrm{B}(\mathrm{c}), \mathrm{C}(\mathrm{d})$ and $\mathrm{D}(\mathrm{e})$.

corresponding average fibre contents $\left\langle f_{\mathrm{s}}^{+}\right\rangle,\left\langle f_{\mathrm{s}}^{-}\right\rangle$and $\left\langle f_{\mathrm{c}}\right\rangle$ have also been determined. The average value of the fibre content in the skins approaches $12 \%$, that in the core zones $21.5 \%$. Notice that the estimated average fibre content in the layers is $18.8 \%$. Hence, despite the difficulties encountered to get an accurate estimate of the fibre content from the X-ray microtomographs (cf. Section 3.2), this value is rather close to the value of $17.4 \% \pm 1 \%$ obtained previously on the same SMC with a charring-weighting technique [17]. 


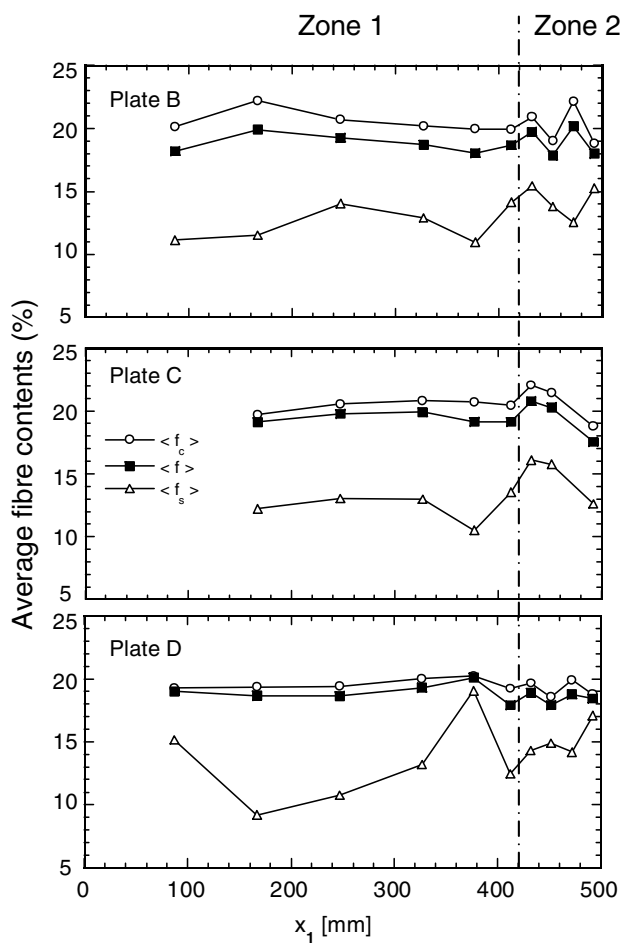

Fig. 5. Evolution of the average values of the fibre contents $\left\langle f_{\mathrm{c}}\right\rangle,\left\langle f_{\mathrm{s}}\right\rangle,\langle f\rangle$ along the flow direction $x_{1}$ of compression moulded plates $\mathrm{B}, \mathrm{C}$ and $\mathrm{D}$.

- The average porosity $\langle\phi\rangle$ in the non-deformed sample A is approximately $6.4 \%$. It is consistent with that estimated on a non-cured industrial SMC by [15]. The dashed-dotted lines delimiting the interfaces between stacked layers have also been drawn in Fig. 4b. Around these interfaces, the porosity is found to be higher than in the core of the layers, except for the upper layer 5. In that layer, the average porosity $\left\langle\phi_{1}\right\rangle$ equals $25 \%$ whereas $\left\langle\phi_{1}\right\rangle$ is smaller in the other layers. Such a higher pore content is also visually confirmed on the $3 \mathrm{D}$ microtomograph shown in Fig. 3a. It is probably induced by the heating of the samples and may be correlated to thermally activated coalescence and rising motion, before complete cross-linking of the polyester resin, of gaseous components of SMC, such as entrapped air and boiling styrene bubbles [30].

- There is a strong contrast between the profile of the volume fraction of fibres $f$ in the non-deformed sample $\mathrm{A}$ and those measured in the deformed samples $\mathrm{B}_{i}, \mathrm{C}_{i}$ and $\mathrm{D}_{i}$ : the interfaces between the initial SMC layers have disappeared. The microstructures of the whole deformed samples reduce to core zones, in which the fibre content is high and fairly constant $(f \geqslant 20 \%)$, and to upper and lower skins near the interfaces between the mould and the samples, where the fibre content is much lower. Whatever the moulding conditions, the initial SMC temperatures, the sample location, and even if the lower skins were in contact with the hot mould surface for approximately $10 \mathrm{~s}$ before flowing, the thicknesses $\mathrm{e}^{+}$and $\mathrm{e}^{-}$of the upper and lower skins of the
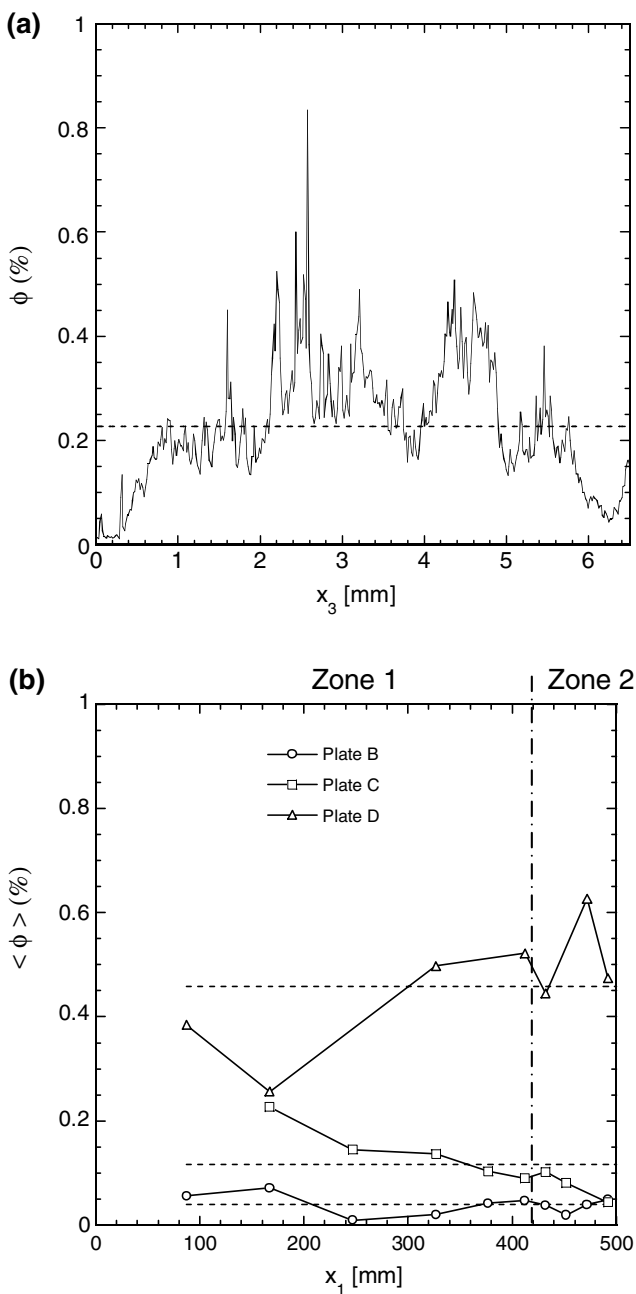

Fig. 6. Evolution (a) of the porosity $\phi$ through the thickness $x_{3}$ of the deformed sample $\mathrm{C}_{2}$ and (b) of the average porosity $\langle\phi\rangle$ along the flow direction $x_{1}$ of compression moulded plates $\mathrm{B}, \mathrm{C}$ and $\mathrm{D}$.

deformed samples are both very close and equal in average to $0.22 \mathrm{~mm}$ and $0.26 \mathrm{~mm}$, respectively. Moreover, Fig. 5 shows that in a first zone (Zone 1) corresponding approximately to $0<x_{1}<420 \mathrm{~mm}$, the average fibre contents in the skins, the core zone and the samples, i.e. $\left\langle f_{c}\right\rangle$ and $\langle f\rangle$, are almost constant. Behind the flow front (Zone 2, $420 \mathrm{~mm}<x_{1}<500 \mathrm{~mm}$ ), some irregular and weak variations are observed. Similar conclusions were drawn previously, by measuring the fibre content with a charring-weighting technique [17].

- A typical porosity profile in the thickness of the deformed samples is given in Fig. 6a. It is very different from the profile recorded for the non-deformed sample A: it exhibits a skin-core-skin substructure, with a higher pore content in the core zone than in skins. As evident from the micrographs shown in Fig. $3 a$ and $b$ and by comparing Figs. $4 \mathrm{~b}$ and $6 \mathrm{a}$, pores in the deformed sample $\mathrm{C}_{2}$ are much smaller and less dense than those contained in the non-deformed sample A. Fig. 6b proves that the last observation holds for all scanned samples and whatever the moulding conditions: $\langle\phi\rangle \approx 0.04 \%$ 
for plate $\mathrm{B},\langle\phi\rangle \approx 0.12 \%$ for plate $\mathrm{C}$ and $\langle\phi\rangle \approx 0.46 \%$ for plate $\mathrm{D}$, whereas $\langle\phi\rangle \approx 6.4 \%$ for plate $\mathrm{A}$. This figure also illustrates (i) the influence of the mould type, e.g. $\langle\phi\rangle$ is slightly higher for the stair plate $\mathrm{C}$ than for the plane plate $\mathrm{B}$, and (ii) the influence of the initial temperature of the SMC charges, e.g. $\langle\phi\rangle$ is lower for the preheated plate $\mathrm{C}$ than for the plate $\mathrm{D}$, initially at room temperature.

\subsection{Analysis of fibrous microstructures}

The two micrographs plotted in Fig. 7a and b respectively represent two slices of the non-deformed sample A close to the lower skin of layer 3 (see Fig. 4, $x_{3}=7.6 \mathrm{~mm}$ ) and in the core of the same layer $\left(x_{3}=9 \mathrm{~mm}\right)$. In accordance with the remarks established in Section 4.1, there are few bundles in the skins, Fig. 7a. By contrast, Fig. 7b shows that in the core of layers, there are lots of rather straight bundles that form an intricate network inside a mixture made of matrix and pores. Fibrous microstructures of deformed samples are quite different and systematically exhibit only two distinct regions, i.e. the skins and the core of samples. For example, slices given in Fig. 7c and d have been respectively taken from the lower skin $\left(x_{3}=0.02 \mathrm{~mm}\right)$ and the core $\left(x_{3}=h / 2\right)$ of the deformed sample $\mathbf{B}_{4}$. Fig. $7 \mathrm{c}$ clearly shows that in these skins, fibre-bundles are severely broken up: bundle descriptors introduced in Section 3.3 are herein not relevant at all. By contrast, bundles are not broken up in core zones (Fig. 7d). They still form a network nearly saturated by the matrix. In these zones, measurements of bending, width, thickness and orientation of bundles may be appropriate.

- The evolutions of the dimensionless width $\left\langle a^{*}\right\rangle$ (with an error $\left.\Delta\left\langle a^{*}\right\rangle= \pm 0.15\right)$ and thickness $\left\langle b^{*}\right\rangle\left(\Delta\left\langle b^{*}\right\rangle= \pm 0.30\right)$ in the core and along the flow direction $x_{1}$ of plates B, $\mathrm{C}$ and D are shown in the graphs (a) and (b) of Fig. 8, respectively. To plot these graphs, the initial average width $\left\langle a_{0}\right\rangle$ and thickness $\left\langle b_{0}\right\rangle$ were determined from measurements performed on the non-deformed sample A and were found to equal $0.74 \pm 0.15 \mathrm{~mm}$ and
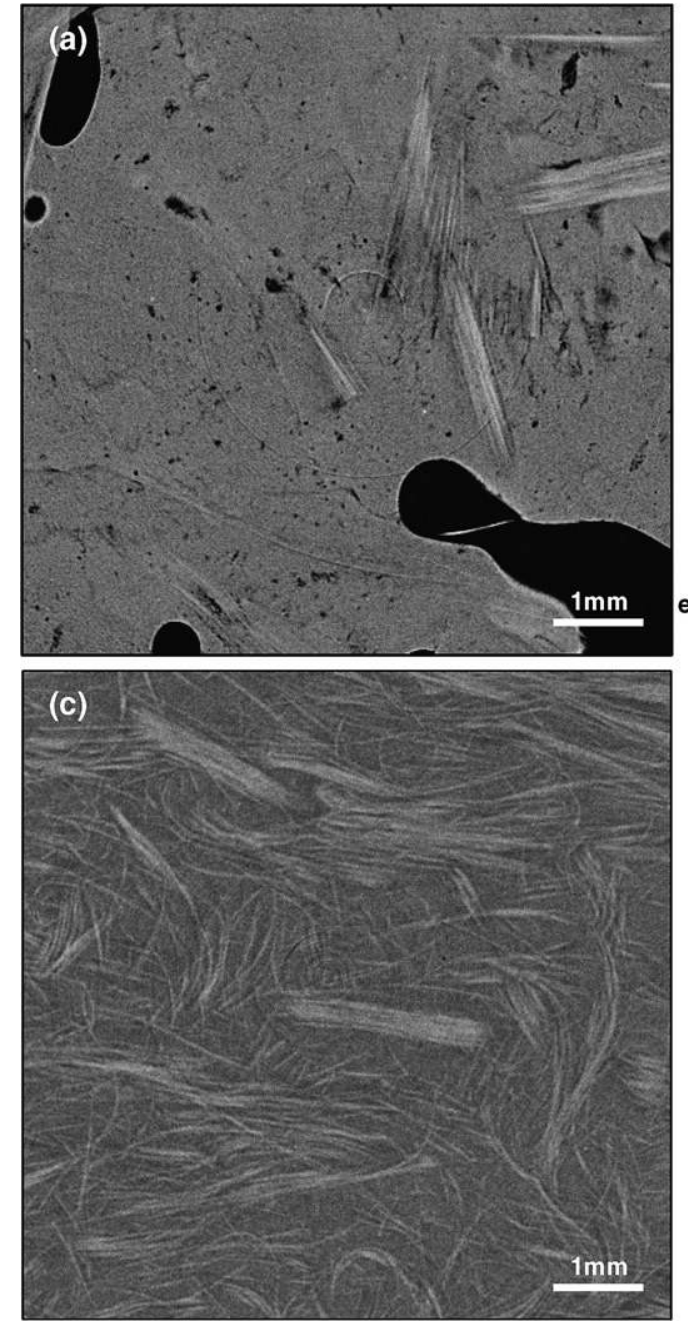

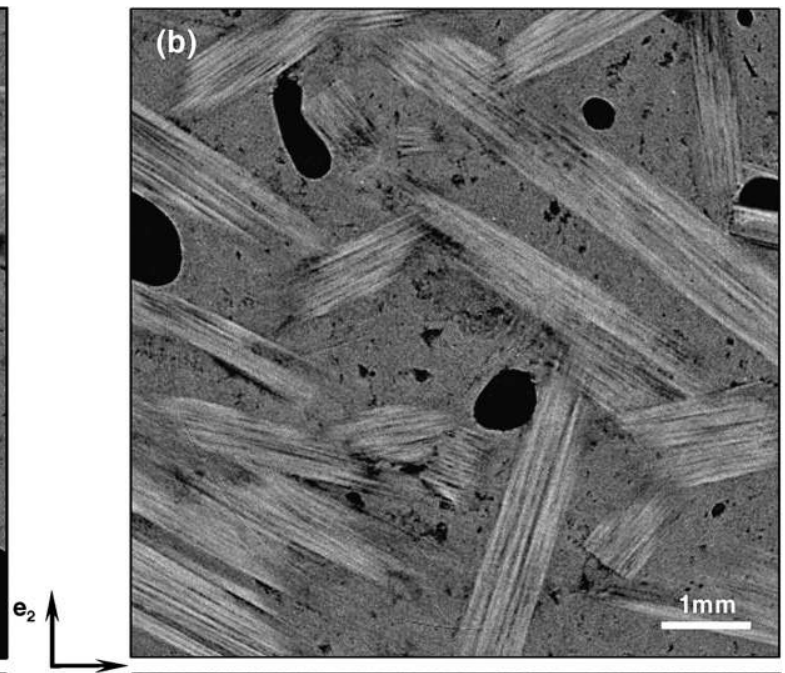

$\mathbf{e}_{1}$

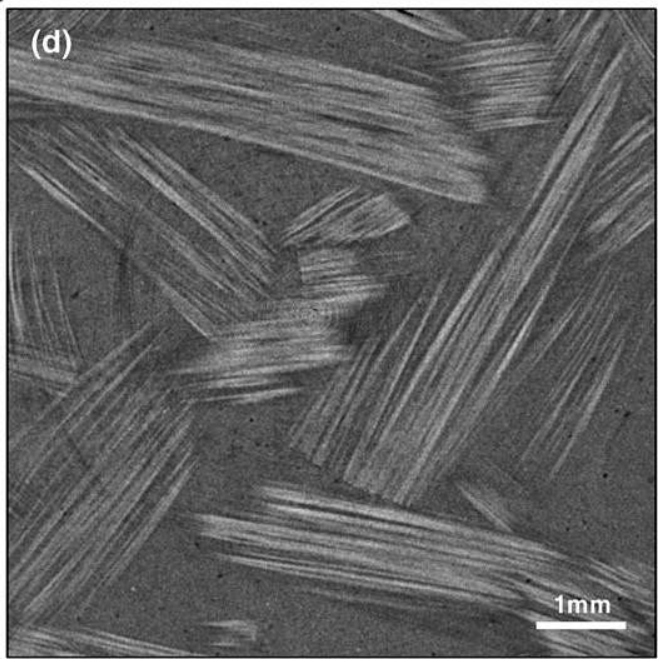

Fig. 7. 2D micrographs of the non-deformed sample $\mathrm{A}$ (a and b) and a compression moulded sample $\mathrm{B}_{4}$ (c and d), close to the skin ((a and c), $\left.x_{3}=0.02 \mathrm{~mm}\right)$ and in the middle of samples $\left((\mathrm{b}\right.$ and $\left.\mathrm{d}), x_{3}=h / 2\right)$. 


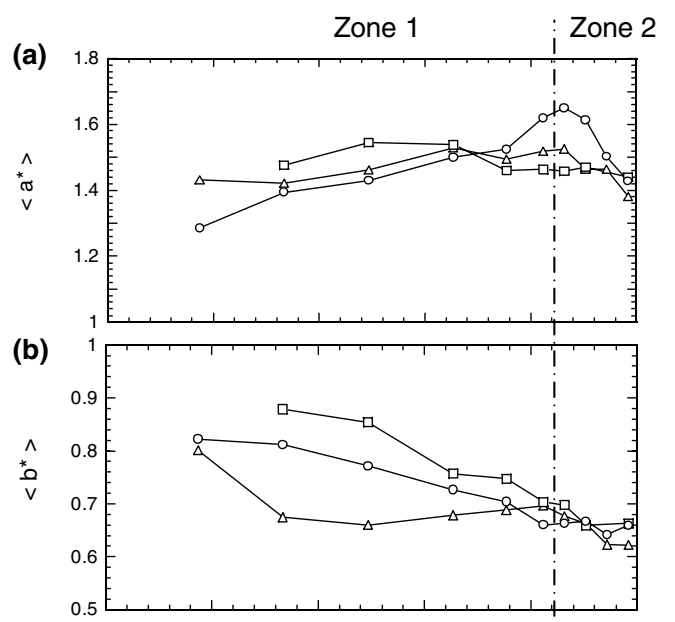

(c)

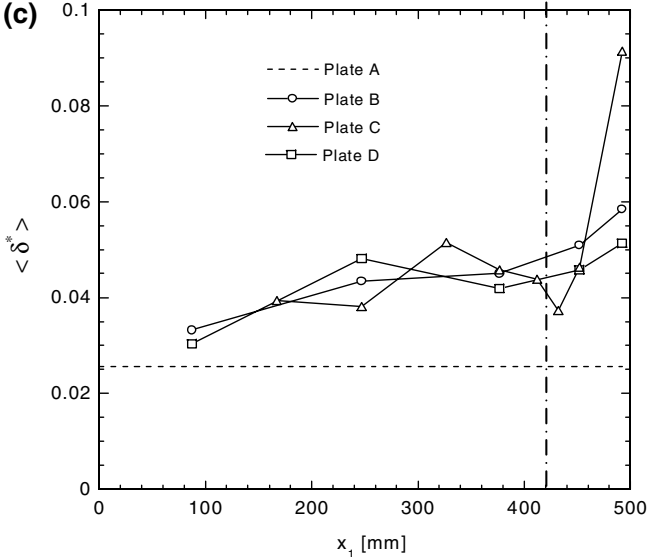

Fig. 8. Evolution of the dimensionless width $\left\langle a^{*}\right\rangle$ (a) and thickness $\left\langle b^{*}\right\rangle$ (b) of the bundles, as well as the dimensionless deflection of bundles $\left\langle\delta^{*}\right\rangle$ (c) in core zones and along the flow direction $x_{1}$ of compression moulded plates $\mathrm{B}, \mathrm{C}$ and $\mathrm{D}$.

$0.09 \pm 0.02 \mathrm{~mm}$, respectively. Whatever the considered moulded plate and the location of the analysed sample, compression moulding induces a significant enlargement of fibre-bundles, which is approximately constant and displays a mean value $\left\langle a^{*}\right\rangle \approx 1.48$, see Fig. 8a. A same trend has been observed when deforming a model transparent bundle suspension with similar bundles [19]. Fig. $8 \mathrm{~b}$ also shows that compression moulding induces a noteworthy reduction of the thicknesses of fibre-bundles, which increases slightly along the flow direction $x_{1}$, whatever the considered plate: for small $x_{1}$ values $\left\langle b^{*}\right\rangle \approx 0.82$ whereas $\left\langle b^{*}\right\rangle \approx 0.63$ near the flow front.

- For the non-deformed sample A, a limited initial bending $\left\langle\delta_{\text {init }}^{*}\right\rangle \approx 0.025$ with a large scattering of $\Delta\left\langle\delta_{\text {init }}^{*}\right\rangle \pm 0.025$ is recorded [19]. This may be induced by the impregnation phase during the processing of SMC layers. Fig. 8c depicts the evolution of the dimensionless in-plane bending $\left\langle\delta^{*}\right\rangle\left(\Delta\left\langle\delta^{*}\right\rangle \pm 0.025\right)$ of fibrebundles in the core zones and along the length $x_{1}$ of compression moulded plates $\mathrm{B}, \mathrm{C}$ and $\mathrm{D}$ : the bending $\left\langle\delta^{*}\right\rangle$ is higher than $\left\langle\delta_{\text {init }}^{*}\right\rangle$ and increases slightly near the flow front (Zone 2). It remains however rather weak, since $\left\langle\delta^{*}\right\rangle$ never exceeds 0.09 and does not appear to cor- relate with the studied moulding conditions. From these results it also is concluded that the method proposed in Section 3.3 to determine the orientation of bundles is relevant.

- The orientation of fibre-bundles was measured in the non-deformed sample A, leading to the following orientation tensor

$$
\begin{aligned}
\underline{\underline{\boldsymbol{A}}} & \approx\left(\begin{array}{ccc}
0.540 & -0.054 & -0.008 \\
-0.054 & 0.459 & -0.011 \\
-0.008 & -0.011 & 0.001
\end{array}\right)_{\left(\underline{e}_{1}, \underline{e}_{2}, \underline{e}_{3}\right)} \\
& =\left(\begin{array}{ccc}
0.567 & 0 & 0 \\
0 & 0.432 & 0 \\
0 & 0 & 0.001
\end{array}\right)_{\left(\underline{\underline{e}}_{I}, \underline{e}_{I I}, \underline{e}_{I I I}\right)}
\end{aligned}
$$

respectively expressed in the mould reference frame $\left(\underline{e}_{1}\right.$, $\left.\underline{\boldsymbol{e}}_{2}, \underline{\boldsymbol{e}}_{3}\right)$ and in its principal reference frame $\left(\underline{\boldsymbol{e}}_{I}, \underline{\boldsymbol{e}}_{I I}, \underline{\boldsymbol{e}}_{I I I}\right)$. Notice that $\mathrm{A}_{I I I} \approx 0, \quad \underline{\boldsymbol{e}}_{I I I}=0.017 \underline{\boldsymbol{e}}_{1}+0.026 \underline{\boldsymbol{e}}_{2}+$ $0.999 \underline{e}_{3} \approx \underline{e}_{3}$. Hence, these results show that before compression moulding, fibre-bundles are mainly orientated in the $\left(\underline{\boldsymbol{e}}_{1}, \underline{\boldsymbol{e}}_{2}\right)$ plane of the sheets and slightly orientated along the $\underline{\boldsymbol{e}}_{1}$ direction as a result of the early compounding stages of SMC.

- Similar measurements were performed in core zones of deformed samples $\mathrm{B}_{i}, \mathrm{C}_{i}$ and $\mathrm{D}_{i}$. As in the case of sample $\mathrm{A}$, the out-of-plane components $\mathrm{A}_{3 i}=\mathrm{A}_{i 3}(i \in\{1,2,3\})$ of the corresponding orientation tensors were found to be very small compared to the in-plane components $\mathrm{A}_{i j}(i, j \in\{1,2\})$, i.e. $\mathrm{A}_{I I I} \approx 0$ and $\underline{\boldsymbol{e}}_{I I I} \approx \underline{\boldsymbol{e}}_{3}$ : graphs plotted in Fig. 9 show the evolution of $\mathrm{A}_{11}$ and $\mathrm{A}_{33}$ along the flow direction $\underline{e}_{1}$ of the three compression moulded plates. As evident from these graphs, $A_{11} \gg A_{33}$, whatever the moulded plate and the considered sample. We have also plotted in the same graphs the evolution of both the major principal value $\mathrm{A}_{I}$ as well as the angle $|\theta|$ the major principal vector $\underline{e}_{I}$ makes with the flow direction $\underline{e}_{1}$. Some of the corresponding orientation ellipses have been plotted above the graphs (the ellipses are aligned with the principal $2 \mathrm{D}$ reference frame $\left(\underline{\boldsymbol{e}}_{I}, \underline{\boldsymbol{e}}_{I I}\right)$ and their major and minor axes respectively equal $\mathrm{A}_{I}$ and $\mathrm{A}_{I I}=1-\mathrm{A}_{I}$ ). Hence, it can be concluded from these graphs that the orientation of bundles within the compression moulded plates exhibits two more or less distinct zones. In zone 1, compression moulding has induced a significant orientation of bundles along the flow direction $\underline{\boldsymbol{e}}_{1}$, i.e. $|\theta| \leqslant 30^{\circ}$, which intensity $\mathrm{A}_{I}$ is roughly constant: $\mathrm{A}_{I}$ ranges between 0.7 and 0.8 for the flat plate $\mathrm{B}$, whereas it ranges between 0.65 and 0.75 for the stair plates $C$ and $D$. In zone 2 , the intensity of the orientation of bundles is less pronounced than in zone $1\left(\mathrm{~A}_{I} \approx 0.5\right)$.

\section{Discussion}

It is important to notice that the previous results have been obtained only for a small number of scanned samples: 


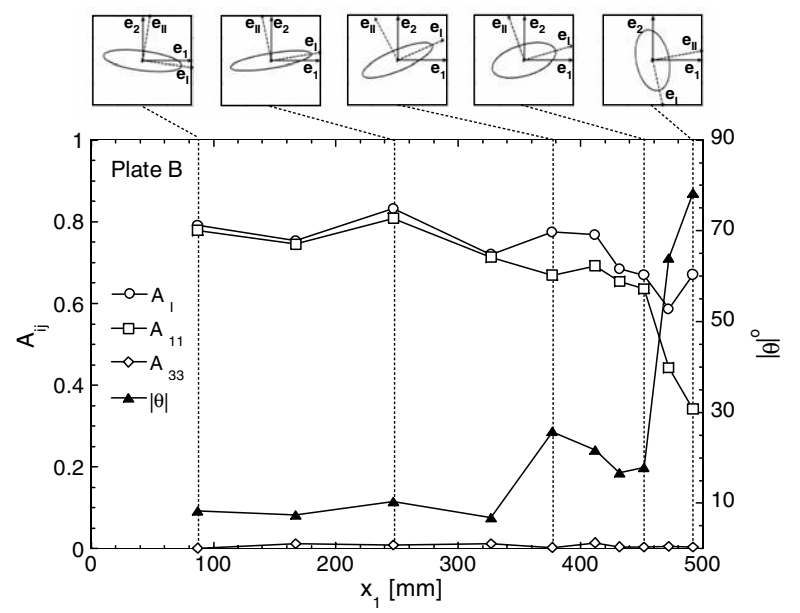

during the compression moulding of plates under industrial processing conditions, the plug flow was the dominant flow mechanism. Plug flow is characterised by (i) uniform inplane elongational and shear deformations of stacked SMC layers, (ii) absence of out-of-plane shear deformation in the stacked layers and (iii) out-of-plane shearing of richpaste boundary layers close to the surface of the moulds. More recent in situ observations of SMC layers during compression moulding have given more detailed insights on the SMC flow mechanisms [30]. Indeed, in the early stage of compression, a first and short "squish" phase may be observed near the flow front: upper and lower layers may be ejected (at least partially) from the stack, leading to very complex flow mechanisms. This phase is then followed by a steady plug flow. At the last step of compression, a "boiling" phase is observed and is related to the boiling of styrene. From the results obtained in this work, it is still possible to complete the above observations:
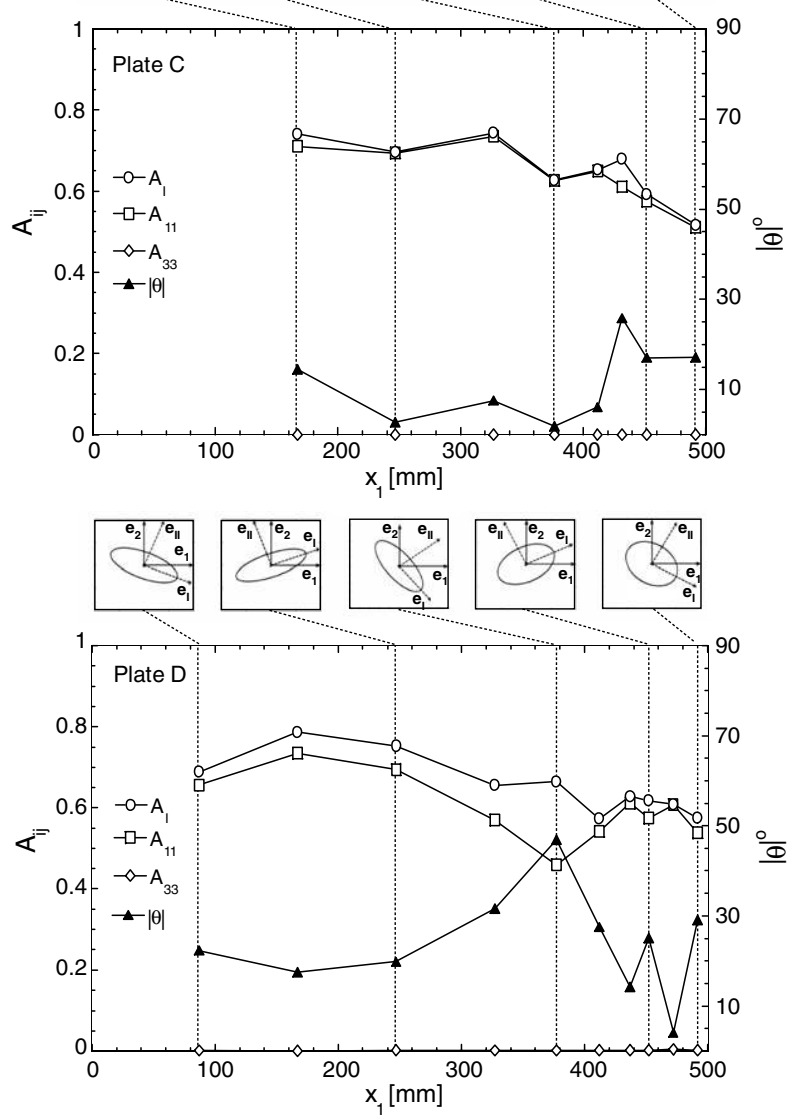

Fig. 9. Evolution of the components $\mathrm{A}_{11}, \mathrm{~A}_{33}$ and $\mathrm{A}_{I}$ of the orientation tensor and the absolute value of the angle $|\theta|$ between the major principal vector $\underline{\boldsymbol{e}}_{I}$ and the flow direction $\underline{\boldsymbol{e}}_{1}$, for compression moulded plates B, C and D.

ongoing work should thus confirm more precisely the above tendencies. However, the following semi-quantitative remarks can already be established from these results.

\subsection{Flow mechanisms at the mesoscopic scale/segregation}

Flow mechanisms of SMC were the issue of a number of previous studies. Barone and Caulk [4] have shown that

- A skin-core-skin substructure has been observed in compression moulded samples. Skins have rather small thicknesses. They exhibit low pore and fibre contents as well as highly broken up fibre-bundles. This latter result tends to prove that during the flowing stage, these zones may be severely sheared. By contrast, bundles have kept their general shape and still form an entangled network in the core zone, even if they are flattened, slightly bent and even if they align with the macroscopic flow direction (cf. next points). This suggests that during the flowing stage, the shear deformation of the network of bundles perpendicular to the $\underline{\boldsymbol{e}}_{3}$ direction is negligible, i.e. its deformation looks like a plug flow. These results are in accordance with the observations performed at the macroscale by Barone and Caulk [4] and Odenberger et al. [30]. They also tend to consolidate some of the assumptions stated by mesoscopic one-phase plug flow models $[1,5,9,10,17,33]$.

- If the average fibre content $\langle f\rangle$ could be considered as roughly constant along the moulded plates (cf. Fig. 5), it has been observed that the matrix-rich interfaces between the bundle-rich layers of the initial samples have completely disappeared after compression (Fig. 4). This indicates that severe segregation phenomena through the thickness of SMC occur during the flowing stage: the initial inner matrix-rich interfaces may be seen as matrix "reservoirs" from which the matrix is sucked up during compression for the formation of the upper and lower skins. It should be noticed that such segregation mechanisms could have a crucial impact on the surface quality of moulded SMC parts. Likewise, even if the mentioned one-phase plug flow models may be adapted, in some average sense, to describe the overall SMC flow during compression moulding, they are unfortunately not able to capture such segregation phenomena. In order to account for them, it is necessary to develop mesoscopic multi-phase models [18] with appropriate permeation laws to 
describe the flow of the non-Newtonian matrix through anisotropic fibrous media $[8,23,31,32,42]$.

- Within the investigated moulding conditions, two (more or less) distinct zones have been observed in compression moulded parts: the flow front zone, i.e. zone 2, and the rest of compression moulded parts, i.e. zone 1 . In zone 2 , the average fibre content exhibits slight variations, bundles seem to be more compacted and bent than in the zone 1, and their orientation remains close to the initial orientation of bundles. If a close analysis of the phenomena happening in the zone 2 would be required, the last observation suggests that flow mechanisms near the flow front may be different from those in the rest of the parts: it would be interesting to see if the above results can be related with the squish flow phase observed in the earlier stages of compression moulding [30].

\subsection{Porosity}

In previous studies, some of the origins of pores in SMC have been identified $[15,30]$ :

- Compounding phase, i.e. paste mixing, fibre-bundle mat impregnation induce air entrapment.

- Stacking of the SMC layers before compression leads to similar mechanisms. This is confirmed by the porosity profile sketched in Fig. $4 \mathrm{~b}$ for the non-deformed sample.

- Rigidity and wetting properties of fibre-bundles, both dependent on the types of sizing and over-sizing, affect the porosity content of compression moulded parts. Typically, the higher the rigidity, the higher the porosity.

- Squishing that may occur at the onset of flow can also lead to air entrapment.

- Curing which induces the boiling of styrene, is also at the origin of porosity (upper layer of Fig. 4b).

On the opposite, other factors tend to reduce porosity:

- Flow mechanisms within matrix-rich skins [15] have shown that the surface porosity was lower than the porosity in the core of compression moulded parts. Results obtained in this work confirm this observation (Fig. 6a). The intense and complex flow combined with the low fibre content within the upper and lower skins are suspected to be responsible for such porosity profiles.

- Mould closing pressure, among all the possible processing parameters affecting porosity, the mould closing pressure at the end of the flowing stage can play a significant role by limiting the expansion of gaseous phases entrapped in compounds during curing. In order to illustrate this, we have gathered in the graph of Fig. 10 experimental data collected (i) from the work of [15] (formulations A1, A2, A3, before and after compression with a maximum axial force exerted by the press of $100 \mathrm{kN}$ and a in-plane dimensions of the mould $203 \mathrm{~mm} \times 203 \mathrm{~mm}$ ) and (ii) from this study (samples A and D), i.e. from rather similar SMC formulations and processing conditions. This graph emphasizes a noteworthy decrease of the average porosity $\langle\phi\rangle$ with the average mould closing pressure $p$.

- Preheating of SMC layers: from results gained in the present study, it is also shown that preheating of SMC layers at moderate temperature (far below the boiling temperature of styrene) and for a moderate time (before the curing of the polyester resin) also affects porosity and may be a proper way to reduce pores in compression moulded parts. This is revealed in Fig. 10 where values deduced from sample $C$ have also been added. By diminishing the viscosity of the matrix $[28,29]$, such a preheating should facilitate the transport of pores from the core of the SMC stack layers to the skins.

\subsection{Deformation of bundles in core zones}

The deflection of bundles in core zones is rather weak before and after compression and exhibits a large scattering. This results shows that bundles display a sufficiently high bending rigidity to sustain forces and moments they are subjected to during compounding and compression moulding. Consequently, bundle networks models that assume in-plane rigid motion of bundles [3,26,27,37,41] should be rather well-suited to model the rheology of SMC, as a first approximation. Their predictions could also be improved by accounting for the bending of bundles, in a similar way to what was carried out in cases of flexible fibre networks models $[25,38]$.

Compression induces significant widening and flattening of bundles (Fig. 8a and b). For instance, in the case of plate $\mathrm{B}$, the average in-plane (or widening) strain of bundles, i.e. $\varepsilon_{\mathrm{a}}=\ln \left\langle a^{*}\right\rangle$, approximately equals 0.4 . Similarly, the average out-of-plane (or flattening) strain of bundles, i.e. $\varepsilon_{\mathrm{b}}=\ln \left\langle b^{*}\right\rangle$, approximately equals -0.4 . It is important to underline that these local strains largely differ from the

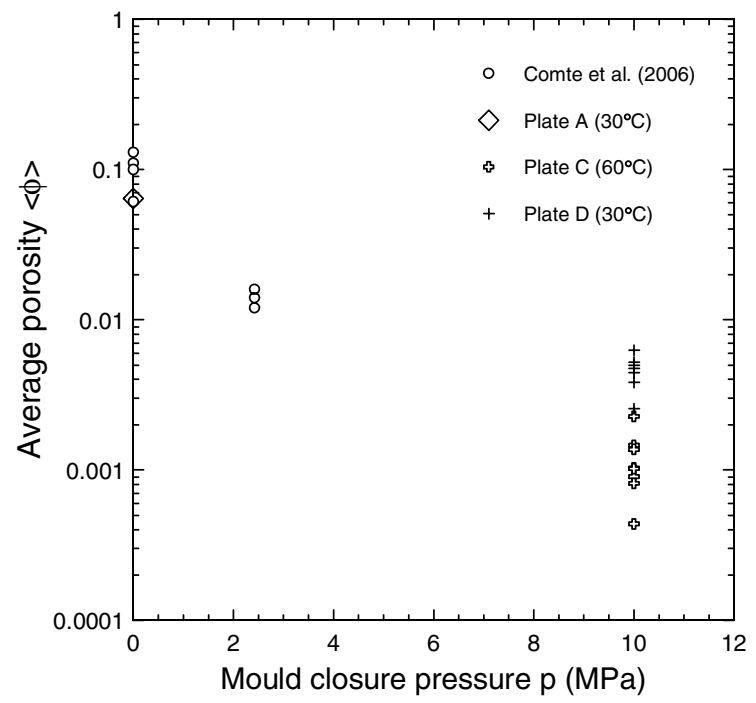

Fig. 10. Evolution of the average porosity $\langle\phi\rangle$ with respect to the mould closing pressure $p$. 
macroscopic strains along the thickness direction $\varepsilon_{33} \approx-1.2$ and the flow direction $\varepsilon_{11} \approx 1.1$ [19]. Moreover, it is wellknown that the rheology of highly concentrated fibre suspensions such as SMC is mainly ruled by the micromechanics of bundle-bundle contacts [27,35,37]. Hence, the observed increase of the width of bundles should lead to an increase of bundle-bundle contact zones, then to an increase of contact forces and moments and finally to an increase of the overall mesoscopic stress tensor required to deform the SMC. To the best of our knowledge, bundle networks models do not account for such micromechanisms.

\subsection{Orientation of bundles in core zones}

It has been seen that the orientation of fibre-bundles was mainly contained in the $\left(\underline{\boldsymbol{e}}_{1}, \underline{\boldsymbol{e}}_{2}\right)$ plane and that bundles tend to align along macroscopic flow direction. We have tried to compare these experimental trends with the prediction given by a 2D Jeffery-based equation for the evolution of the second order orientation tensor $\underline{\boldsymbol{A}}[24,2]$. This equation is usually well-suited to predict fibre-orientation in dilute Newtonian suspensions. To perform this comparison, it was assumed that the bundles were slender bodies and that the bundle network deformed as a homogeneous plug flow during the irrotational compression moulding of plate B. This last assumption should be roughly valid at least in the zone 1 (far from the flow front). Then, the Jeffery equation simply reads:

$\frac{\partial A_{\alpha \beta}}{\partial t}=A_{\alpha \gamma} D_{\gamma \beta}+D_{\alpha \gamma} A_{\gamma \beta}-2 A_{\alpha \beta \gamma \delta} D_{\gamma \delta}$,

where $\alpha, \beta, \gamma, \delta \in\{1,2\}, D_{\alpha \beta}$ represents the $2 \mathrm{D}$ components of the macroscopic strain rate tensor $\underline{\boldsymbol{D}}$ and where the components $\mathrm{A}_{\alpha \beta \gamma \delta}$ of the fourth-order orientation tensor have been approximated using the natural closure approximation [20]. By using the experimental values of $\boldsymbol{A}$ of the non-deformed sample A as initial conditions, the computed value $A_{11}$ of the second order orientation tensor at the end of compression is $\approx 0.82$. This predicted value follows the experimental trend but it is slightly higher than the average experimental value in zone 1 , i.e. $\mathrm{A}_{11} \approx 0.75$. It must be pointed out that a similar overestimate has been observed in the case of the homogeneous plane strain compression of transparent model bundle suspensions [19]. The observed discrepancy is mainly ascribed to the non-Newtonian rheology of the pasty matrix and to the very high fibre content of SMC, largely above the dilute and semi-dilute regimes.

\section{Conclusion}

The phase contrast microtomography was used to analyse the microstructure of non-deformed and deformed samples of SMC. This technique permitted to reconstruct 3D images of the microstructure of the SMC samples and to detect and differentiate the pores, the filled polymermatrix and the fibre-bundles. This study was essentially aimed at analysing fibre-bundles before and after compression. Consequently, the required voxel size did not allow proper observation of fibres as well as micropores inside bundles: smaller voxel size (and hence smaller size of samples) could be used in order to focus the analysis on possible micropores contained inside the fibres of given bundles. Moreover, it was also shown that the contrast between the matrix and the fibre-bundles was however not sufficient enough (i) to get accurate estimates of the absolute volume fraction of fibres; (ii) to allow automatic image analysis of scanned volumes. A possible solution to further enhance the contrast between the matrix and the fibres would consist in using the holotomography $[6,13]$. This solution will be explored in future work. However, by analysing these images with simple and rather reliable methods, it was possible to quantify various microstructure descriptors such as the deflection, widening, flattening and the $3 \mathrm{D}$ orientation of bundles. Some estimates of the volume fraction of pores and fibres through the thickness and along the flow direction of moulded parts were also reported.

- The substructures of initial SMC layers and compression moulded parts through their thicknesses exhibit three distinct regions: cores zones sandwiched between two skins. In cases of initial SMC layers, such substructures are directly connected with the compounding phase, whereas compression moulding induces it in cases of deformed samples.

- Within the skins of deformed samples, the porosity as well as the fibre content is much lower than in core zones, and the rare bundles are severely broken up. This suggests that these zones are highly sheared during compression. By contrast, the network of bundles is preserved in the cores zones of compression moulded parts. This tends to prove that shearing through the thickness of core zones is weak and that networks of bundles deform following plug flow modes.

- Within core zones, bundles slightly bend, significantly widen and flatten. Such microscopic deformation modes largely differ from the macroscopic deformation to which the samples are subjected during compression.

- Almost no fibre-matrix separation was observed in the plane of the tested compression moulded parts, since the average fibre content along the flow direction is kept approximately constant. In parallel, the inner skins of the initial stacked layers have disappeared after compression. This reveals that strong matrix migration occurs through the thickness of parts during compression moulding and contributes to the formation of skins.

- During compression, the porosity decreases sharply in the core of moulded samples and even more in their skins. Furthermore, it has been shown that the average porosity is a decreasing function of the average mould closing pressure and that a preheating of SMC layers can be beneficial to achieve a lower pore content. 


\section{Acknowledgements}

We would like to thank the Research Federation CNRS 2145 "Structural Materials and their Properties" for its financial support.

\section{References}

[1] Abrams L, Castro J. Predicting molding forces during sheet molding compound (SMC) compression molding. I. Model development. Polym Compos 2003;24:291-303.

[2] Advani SG, Tucker CL. The use of tensors to describe and predict fiber orientation in short fiber composites. J Rheol 1987;3(8):751-84.

[3] Ausias G, Fan XJ, Tanner RI. Direct simulation for concentrated fibre suspensions in transient and steady state shear flows. J NonNewton Fluid Mech 2006;135:46-57.

[4] Barone M, Caulk D. Kinematics of flow in sheet molding compound. Polym Compos 1985;6(2):105-9.

[5] Barone MR, Caulk DA. A model for the flow of a chopped fiber reinforced polymer compound in compression molding. J Appl Mech 1986;53(191):361-70.

[6] Baruchel J, Di Michiel J-YBPCM, Ferrie E, Ludwig W, Maire E, Salvo L. Advances in synchrotron radiation microtomography. Script Mater 2006;55:41-6.

[7] Bay SR, Tucker III CL. Stereological measurement and error estimates for three-dimensional fiber orientation. Polym Eng Sci 1992;32:240.

[8] Bruschke MV, Advani SG. Flow of generalized newtonian fluid across a periodic array of cylinders. J Rheol 1993;37(3):479-98.

[9] Castro J, Griffith R. Sheet molding compound compression-molding flow. Polym Eng Sci 1989;29(10):632-8.

[10] Castro J, Griffith R. Mathematical modeling of the in-mold coating process. Polym Eng Sci 1990;30(11):677-83.

[11] Christensen S, Hutchinson B, Sun E, Osswald T, Davis B. Fibermatrix separation in ribbed SMC and BMC parts. In: ANTEC, editor. Proceedings of the Ann. Tech. Conference - ANTEC. Soc. of Plastics Engineers. CT, USA: Brookfield; 1997. p. 782-7.

[12] Cloetens P, Barrett R, Baruchel J, Guigay J-P, Schlenker M. Phase objects in synchrotron radiation hard X-ray imaging. J Phys D: Appl Phys 1996;29:133-46.

[13] Cloetens P, Ludwig W, Baruchel J, Van Dick D, Van Landuyt J, Guigay J-P, et al. Holotomography: quantitative phase tomography with micrometer resolution using hard synchrotron radiation X-rays. Appl Phys Lett 1999;75:2912-4.

[14] Cloetens P, Ludwig W, Guigay J.-P, Baruchel J, Dick MSD. X-ray Tomography in Material Science, Hermes. Chapter Phase Contrast Tomography. 2000. p. 115-25.

[15] Comte E, Mehri D, Michaud V, Månson J-A. Void formation and transport during SMC manufacturing: effect of the glass fiber sizing. Polym Compos 2006;27:289-98

[16] Dumont P, Orgéas L, Le Corre S, Favier D. Anisotropic viscous behaviour of sheet molding compounds (SMC) during compression molding. Int J Plast 2003;19(4):625-46.

[17] Dumont P, Orgéas L, Favier D, Pizette P, Venet C. Compression moulding of SMC: in situ experiments, modelling and simulation. Compos Part A 2007;38:353-68.

[18] Dumont P, Le Corre S, Orgéas L, Favier D, Gaborit C, Lory P. Finite element implementation of a two-phase model for compression molding of composites. Euro J Comput Mech 2005;14:883-900.

[19] Dumont P, Vassal J-P, Orgéas L, Michaud V, Favier D, Månson JAE. Processing, characterization and rheology of transparent concentrated fibre bundle suspensions. Rheol Acta 2007;46:639-51.
[20] Dupret F, Verleye V. Modelling the flow of fiber suspensions in narrow gaps. Rheology series. Amsterdam: Elsevier; 1999, p. 134798.

[21] Eberhardt C, Clarke A, Vincent M, Giroud T, Flouret S. Fibreorientation measurements in short-glass-fibre composites. II. A quantitative error estimate of the $2 \mathrm{D}$ image analysis technique. Compos Sci Technol 2001;61:1961-74.

[22] Feuillade V, Bergeret A, Quantin J-C, Crespy A. Relationships between the glass fibre sizing composition and the surface quality of sheet moulding compounds (SMC) body panels. Compos Sci Technol 2006;66:115-27.

[23] Idris Z, Orgéas L, Geindreau C, Bloch J-F, Auriault J-L. Microstructural effects on the flow law of power-law fluids through fibrous media. Model Simul Mater Sci Eng 2004;12:995-1015.

[24] Jeffery GB. The motion of ellipsoidal particles immersed in a viscous fluid. Proc Roy Soc London (A) 1922;102:161-79.

[25] Joung CG, Phan-Thien N, Fan XJ. Direct simulation of flexible fibers. J Non-Newtonian Fluid Mech 2001;99:1-36.

[26] Le Corre S, Caillerie D, Orgéas L, Favier D. Investigation of the squeeze flow behaviour of sheet moulding compounds (SMC). J Mech Phys Solids 2004;52:395-421.

[27] Le Corre S, Dumont P, Orgéas L, Favier D. Rheology of highly concentrated planar fiber supensions. J Rheol 2005;49:1029-58.

[28] Le Corre S, Orgéas L, Favier D, Tourabi A, Maazouz A, Venet C. Shear and compression behaviour of sheet moulding compounds. Compos Sci Technol 2002;62:571-7.

[29] Lee LJ, Marker LF, Griffith RM. The rheology and mold flow of polyester sheet molding compound. Polym Compos 1981;2:209-18.

[30] Odenberger P, Andersson H, Lundström T. Experimental flow-front visualisation in compression moulding of SMC. Compos Part A 2004;35:1125-34.

[31] Orgéas L, Idris Z, Geindreau C, Bloch J-F, Auriault J-L. Modelling the flow of power-law fluids through anisotropic porous media at low pore Reynolds number. Chem Eng Sci 2006;61:4490-502.

[32] Orgéas L, Geindreau C, Auriault J-L, Bloch J-F. Upscaling the flow of generalised Newtonian fluids through anisotropic porous media. $\mathrm{J}$ Non-Newtonian Fluid Mech 2007;145:15-29.

[33] Osswald T, Tucker C. Compression mold filling simulation for nonplanar parts. Int J Polym Process 1990;5:79-87.

[34] Osswald T, Tseng S.-C. Flow and rheology in polymer composites manufacturing, vol. 10 of Composites materials series. Chapter 10. Compression Molding. Elsevier; 1994. p. 361-413.

[35] Petrich MP, Koch DL. Interactions between contacting fibers. Phys Fluids 1998;10(8):2111-3.

[36] Rolland du Roscoat S, Decain M, Thibault X, Geindreau C, Bloch J-F. Estimation of microstructural properties from synchrotron $\mathrm{X}$-ray microtomography and determination of the REV in paper materials. Acta Mater. 2007;55:2841-50.

[37] Servais C, Luciani A, Månson J-AE. Fiber-fiber interaction in concentrated suspensions: dispersed fiber bundles. J Rheol 1999;43(4):1005.

[38] Switzer LH, Klingenberg DJ. Flocculation in simulations of sheared fiber suspensions. Int J Multiphase Flow 2004;30:67-87.

[39] Teyssier S, Bres S, Ohl B, Merle G. Global analysis of orientation in BMC and relation with mechanical properties. In: SME, editor. Proceedings ICCM-14. San Diego, USA: SME; 2003. p. 1-9.

[40] Thomasson JL, Vlug MA. Influence of fibre length and concentration on the properties of glass fibre-reinforced polypropylene. 1. Tensile and flexural modulus. Compos Part A 1996;27A:477-84.

[41] Toll S, Månson J-AE. Dynamics of a planar concentrated suspension with non-hydrodynamic interaction. J Rheol 1994;38(4):985-97.

[42] Woods JK, Spelt PDM, Lee PD, Selerland T, Lawrence CJ. Creeping flows of power-law fluids through periodic arrays of elliptical cylinders. J Non-Newtonian Fluid Mech 2003;111:211-28. 